\title{
Capsule Commentary on Haas et al., Provider Attitudes and Screening Practices Following Changes in Breast and Cervical Cancer Screening Guidelines
}

\author{
Ramzi G. Salloum, PhD \\ Department of Health Outcomes and Policy, University of Florida College of Medicine, Gainesville, FL, USA.
}

J Gen Intern Med 31(1):103

DOI: $10.1007 / \mathrm{s} 11606-015-3490-4$

(c) Society of General Internal Medicine 2015

$\mathrm{T}$ he most recent U.S. Preventive Services Task Force (USPSTF) recommendations call for a reduction in the frequency of and eligible age ranges for breast cancer (2009) and cervical cancer screening (2012). These changes have stirred controversy over care rationing and resulted in additional complexity for primary care providers. In this issue of JGIM, Haas et al. ${ }^{1}$ present a timely assessment of provider self-reported attitudes and practice changes toward breast and cervical cancer screening following the latest USPSTF recommendations. While cancer screening is critical to public health, overuse of screening is costly to the healthcare system and consumes scarce resources.

Haas et al. found that providers prescribed more screening than that endorsed in USPSTF guidelines, especially for breast cancer, and cited patient concerns as the primary barrier to concordance with the recommendations. Provider disagreement with the recommendations and health system measurement of provider screening practices that use conflicting measurement criteria were also common barriers. Cancer screening in excess of the latest guideline recommendations comes as no surprise, given that Medicare coverage for cancer screening has become more generous during the same time period, leading to elimination of cost-sharing requirements. ${ }^{2}$

The study sample was not nationally representative, and preliminary reports suggest that nationwide mammography rates may have decreased in response to the 2009 USPSTF revision. ${ }^{3}$ However, findings for breast screening were consistent with prior surveys of cancer screening practices among primary care providers. ${ }^{4}$ Haas et al. expanded their sample beyond physicians to include nurse practitioners, certified nurse midwives, and physician assistants, and theirs is the first study to observe self-reported cervical cancer screening practices in light of the 2012 changes in cervical screening recommendations.

Provider self-reports alone may be insufficient for evaluating the discussion that occurs between providers and their patients around cancer screening. Screening decisions are complex and are influenced by patientlevel factors and patient-provider communication, and these complex interactions should be considered in the design of future studies. For example, many women may be accustomed to cancer screening at regular intervals, and screening cessation in concordance with guidelines may be viewed as a major decision. ${ }^{5}$

Conflict of interest: The author has no conflicts of interest with respect to this article.

Corresponding Author: Ramzi G. Salloum, PhD; Department of Health Outcomes and PolicyUniversity of Florida College of Medicine, PO Box 100177, Gainesville, FL 32610, USA (e-mail: rsalloum@ufl.edu).

\section{REFERENCES}

1. Haas JS, Sprague BL, Klabunde CN, Tosteson ANA, Chen JS, Bitton A, et al. Provider attitudes and screening practices following changes in breast and cervical cancer screening guidelines. J Gen Intern Med. doi:10.1007/ s11606-015-3449-5.

2. Salloum RG, Kohler RE, Jensen GA, Sheridan SL, Carpenter WR, Biddle AK. U.S. Preventive Services Task Force recommendations and cancer screening among female Medicare beneficiaries. J Womens Health. 2014;23(3):211-7.

3. Jiang M, Hughes DR, Duszak R. Screening mammography rates in the Medicare population before and after the 2009 U.S. Preventive Services Task Force guideline change: an interrupted time series analysis. Womens Health Issues. 2015;25(3):239-45.

4. Corbelli J, Borrero S, Bonnema R, McNamara M, Kraemer K, Rubio D, et al. Physician adherence to U.S. Preventive Services Task Force mammography guidelines. Womens Health Issues 2014; e313-9.

5. Torke AM, Schwartz PH, Holtz LR, Montz K, Sachs GA. Older adults and forgoing cancer screening: "I think it would be strange.". JAMA Intern Med. 2013;173:526-31. 